\title{
Apropiación del agua y configuración hidrosocial en los Altos de Jalisco (1935-2017)
}

\section{Appropriation of Water and Hydrosocial Configuration in los Altos de Jalisco (1935-2017)}

\author{
Antonio Rodríguez Sánchez \\ (1) 0000-0003-2788-3918 \\ Instituto de Investigaciones Dr. José María Luis Mora, México \\ handle_tony@hotmail.com
}

Resumen: En este artículo se examina el proceso de apropiación del agua en los Altos de Jalisco por parte de actores como instituciones, terratenientes, campesinos, agroindustriales, entre otros, quienes por más de 70 años han negociado e impuesto formas de acaparamiento. Para identificar a dichos actores se realizaron entrevistas y se consultaron documentos de archivo. Así, se encontró que la apropiación del agua se concretó a través de relaciones de poder, cuyo resultado fue la configuración de un espacio hidrosocial caracterizado por el acceso al agua para algunos municipios y, en cambio, la marginación paulatina de otros, como Cañadas de Obregón, Valle de Guadalupe y Jalostotitlán. De este modo, los resultados sugieren que los conflictos por el control del agua en la región no son actuales ni espontáneos, sino parte de un proceso histórico que involucra el manejo hídrico nacional y la permanencia de privilegios en grupos hegemónicos regionales.

Palabras clave: espacio hidrosocial; actores sociales; relaciones de poder; apropiación; intensificación y expansión del agua.

Abstract: This article examines the process of water appropriation in los Altos de Jalisco by actors such as institutions, landowners, peasants and agroindustrialists, among others, who for more than seventy years, have negotiated 
and imposed forms of hoarding. In order to identify these actors, interviews were conducted and archival documents consulted. Thus, it was found that the appropriation of water was implemented through power relations, which led to the configuration of a hydrosocial space characterized by access to water for some municipalities and the gradual marginalization of others, such as Cañadas de Obregón, Valle de Guadalupe and Jalostotitlán. The results therefore suggest that the conflicts over water control in the region are neither current nor spontaneous, but part of a historical process that involves national water management and the permanence of privileges in regional hegemonic groups.

Key words: hydrosocial space; social actors; power relations; appropriation; water intensification and expansion.

Fecha de recepción: 28 de marzo de 2017 Fecha de aceptación: 10 de julio de 2017

\section{INTRODUCCIÓN}

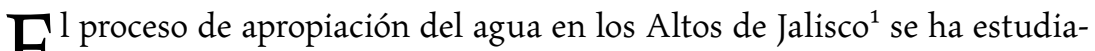
Cdo desde diversas aristas como el suministro de agua a Guadalajara, el proceso de abastecimiento a algún municipio perteneciente a la región y los proyectos de transferencia de agua a otras ciudades dentro y fuera del estado. Asimismo se ha puesto atención a los conflictos que se han desencadenado ante dichas iniciativas. ${ }^{2}$

Sin embargo, los estudios referidos no evidencian que a pesar de los diversos cambios en la ubicación y objetivos de los proyectos que la política hídrica nacional ha implementado a lo largo de 82 años en la región, los municipios Cañadas de Obregón, Valle de Guadalupe, Jalostotitlán y San Miguel

${ }^{1}$ La región se ubica al noreste del estado de Jalisco, debido a la amplitud se dividió administrativamente en dos. La región Altos Norte, y en la que se centra este artículo región Altos Sur; esta comprende los siguientes municipios: Acatic, Arandas, Cañadas de Obregón, Jalostotitlán, Jesús María, Mexticacán, San Ignacio Cerro Gordo, San julián, San Miguel el Alto, Tepatitlán de Morelos, Valle de Guadalupe, Yahualica de Gonzaléz Gallo (Ramírez, 2013).

${ }^{2}$ Algunos ejemplos de estos trabajos son Casillas (2002); Durán y Torres (2006); Escobar (2012). 
el Alto siempre han sido el corazón de los mismos, provocando el desplazamiento progresivo de la mayoría de sus habitantes del acceso al agua para uso productivo, y en la actualidad pretenden inundar sus territorios con la finalidad de construir presas. Por tanto, en este artículo se aborda el tema desde la configuración hidrosocial del espacio, enfoque que permite identificar cómo interactúan los actores para lograr la apropiación del agua y analizar las relaciones de poder establecidas entre terratenientes y funcionarios públicos durante la política de irrigación (1935-1950). También se abarcan el primer proceso de transferencia de agua a Guadalajara entre las décadas de 1940 y 1950 y, por último, los proyectos de trasvase del río Verde entre 1989 y 2017.

\section{CONCEPTO Y ELEMENTOS DE LA CONFIGURACIÓN HIDROSOCIAL DEL ESPACIO}

El término configuración hidrosocial del espacio surge de la teoría de la producción del espacio (Lefebvre, 1993), cuyo método visualiza al espacio (formación social) y al tiempo (procesos sociales) como totalidad, pues se estudian en forma conjunta y necesariamente dialéctica debido a que están en continuo movimiento de acomodo, transformación, construcción, destrucción y reconstrucción. En este sentido, se puede comentar que al relacionarse, tanto la sociedad como la naturaleza son parte de dicha totalidad, ya que producen y reproducen espacio a través del tiempo.

Cabe mencionar que algunos autores adscritos a la geografía crítica (Santos, 1986, Smith, 2006) niegan que haya una separación entre lo social y lo natural y argumentan que la correlación entre ambos aspectos se lleva a cabo con el proceso social del trabajo como intermediario, es decir, la serie de acciones a través de las cuales los seres humanos transforman la naturaleza $y$, a la vez, se transforman ellos mismos. "Con la acumulación del capital

${ }^{3}$ Es la corriente de mayor caudal en los Altos de Jalisco, ya que cerca del poblado de Temacapulín (Cañadas de Obregón) se juntan los cauces de diferentes corrientes; además, atraviesa toda la parte oeste de la región hasta encontrarse con el río Santiago, cerca de Guadalajara. Por el norte, el agua baja desde la sierra "de los negros" entre Yahualica y Nochistlán y desde el sur en la falda septentrional del Cerro Gordo. Durante cuatro meses del año, entre junio y septiembre, grandes cantidades de agua se recolectan en el río Verde, cuyo cauce corre en las profundidades de una barranca, que llega a tener más de 300 metros de profundidad en la confluencia con el río Santiago, a pocos kilómetros de distancia de la zona metropolitana de Guadalajara (Casillas y González, 2009, p. 4).

\section{()(1) $(9$}


y la expansión del desarrollo económico, la naturaleza es cada vez más el resultado de la producción social, cuyo mecanismo se efectúa a través de la apropiación de la naturaleza en la búsqueda de materias primas, con la reproducción de la fuerza de trabajo, la relación trabajo salario y la producción de mercancías" (Smith, 2006, p. 13).

Así, cuando se habla de configuración hidrosocial es necesario subrayar que si bien el agua es parte de la naturaleza y, por lo tanto, está sujeta a una intrínseca relación con la sociedad, tiene un proceso de apropiación particular a través del cual se integra socialmente y es en dicho momento cuando se inicia la configuración hidrosocial del espacio, pues se separa del resto de los elementos naturales a través de la exploración (estudios y análisis) de su funcionamiento, para conocer su cantidad y calidad y así saber cómo explotarla, trasladarla, administrarla y legislarla; es decir, al trabajo extractivo lo antecede uno intelectual, y en él participan actores sociales relacionados con la burocracia hidráulica, cuya influencia en la toma de decisiones respecto a su usufructo y acceso serán fundamentales (Toledo, 2002).

De esta forma, la apropiación del agua genera una configuración hidrosocial del espacio, pues una vez separada de la naturaleza todos sus usos son diversificados, o sea, los actores políticos y económicos llevan a cabo un proceso de intensificación del agua multiplicando sus usos e incrementando su exploración, explotación, traslado y transformación. Intensificación que a su vez deriva en una expansión del líquido, la cual se aprecia con las transferencias hídricas a diferentes escalas, tales como municipales, regionales e interestatales, esto condicionado por los requerimientos de las actividades económicas, cuyo objetivo es la obtención de mayores ganancias.

La intensificación de los usos del agua se puede observar a través de la infraestructura, es decir, las presas, los acueductos y los sistemas de irrigación, por mencionar algunos, con los cuales se busca diversificar su aprovechamiento en sectores como el urbano, el industrial y el agrícola, entre otros. Por su parte, la expansión del agua se advierte mediante las "transferencias" o trasvases que se hacen de región a región a fin de intentar mejorar el nivel de vida, así como las actividades económicas, políticas y sociales de las regiones receptoras, si bien al mismo tiempo resultan perjudicados los mismos rubros de las regiones emisoras, así como su equilibrio ecológico, ya sea a corto, mediano o largo plazos (Harvey, 2001; Swyngedouw, 2009).

También es importante mencionar que la intensificación y la expansión del agua son influenciadas por actores sociales que establecen relaciones

\section{()(1) $(9$}


de poder, las cuales tienen lugar cuando en la trasformación social y física del agua intervienen discursos de legitimación y argumentos que se utilizan para avalar estrategias dirigidas a la apropiación y control del líquido. En otras palabras, dichas prerrogativas serán para aquellos actores o agentes con las capacidades económicas y políticas para influir en la toma de decisiones técnicas que permitan superar los obstáculos geográficos, así como establecer arreglos políticos y legales. En este sentido, se puede afirmar que los derechos comunes al agua pública son transformados económica, política y socialmente en derechos de propiedad, cuyo acceso está determinado por mecanismos de mercado, lo que provoca tensiones entre espacios, como el rural y el urbano, o bien entre lo intrarrural y lo intraurbano (Lefebvre, 1971; Swyngedouw, 2009).

Con base en lo anterior, el agua se integra a la sociedad a través de un proceso en el que se construye una intrincada relación entre la forma de gobierno, la administración y el poder. Correlación mediada por las necesidades políticas, económicas y sociales de los diferentes contextos históricos, las cuales determinarán la intensificación y expansión de los usos del líquido mediante el valor, las formas de aprovechamiento, la contaminación y la cantidad disponible.

En síntesis, la configuración hidrosocial del espacio se entiende como el proceso de apropiación, usufructo y transformación del agua que lleva a cabo la sociedad en diferentes momentos históricos en los que deja su respectiva estructura espacial. Dicho proceso está condicionado por tendencias políticas, económicas y sociales; así, la integración social del agua produce espacio.

Ahora bien, a partir de los argumentos expuestos es posible identificar tres elementos que definen la configuración hidrosocial del espacio: la apropiación del agua, los actores sociales y las relaciones de poder. Dichos elementos se retoman a fin de establecer las diferentes modalidades de apropiación del agua, los actores sociales involucrados, las relaciones de poder establecidas y la paulatina marginación del acceso al agua de los municipios jaliscienses Cañadas de Obregón, Valle de Guadalupe, Jalostotitlán y San Miguel el Alto entre 1935 y 2012.

La apropiación del agua se ve como un proceso cuyo inicio -como ya se comentó- se da cuando los grupos en el poder la fragmentan de la naturaleza utilizando leyes, reglamentos, códigos, entre otros elementos jurídicos, para monopolizar su uso, exploración, explotación, traslado, abastecimiento y modalidades de gestión, así como la construcción de infraestructura.

\section{(1)(1) $(9$}


Los actores sociales son los agentes colectivos o individuales que intervienen en el proceso de apropiación; se identificaron tres tipos:

a) Apropiadores. Son aquellos que estudian, exploran, extraen, reglamentan y distribuyen el agua, definiendo así sus formas de apropiación. Asimismo construyen infraestructura. Entre ellos se encuentran las instituciones encargadas de llevar a cabo las actividades mencionadas y la toma de decisiones respecto a la gestión.

b) Usufructuarios. Son aquellos que se benefician con el reparto y acceso al agua, por ejemplo: agricultores, agroindustriales e industriales.

c) Desplazados. Son aquellos que resultan despojados o menos favorecidos durante el proceso de apropiación y reparto del agua.

Finalmente, las relaciones de poder se entienden como las estrategias y mecanismos utilizados por los apropiadores y usufructuarios para conservar los privilegios y acaparamiento del agua en detrimento de los desplazados.

\section{LA APROPIACIÓN DEL AGUA PARA USO AGRÍCOLA: LA POLÍTICA DE IRRIGACIÓN}

Para el año de 1935 la región de los Altos de Jalisco tenía una estructura espacial esencialmente agrícola y ganadera. Se sembraban productos como el maíz, el frijol y el chile. En cuanto al sector ganadero, se criaba ganado bovino de carne y leche, porcino y ovino. Las largas extensiones de tierra se podían apreciar rotuladas por los arados y el ganado se encontraba pastando en las tierras destinadas para ello. ${ }^{4}$

En su mayoría, la infraestructura hidráulica estaba conformada por pozos artesianos, diques y bordos que servían para contener el agua que se utilizaba para las actividades productivas. La decisión política que alteró la organización espacial y social descrita llegó el 28 de agosto de 1935, cuando Lázaro Cárdenas, entonces presidente de la república, lanzó un importante proyecto a través del cual se creaba el Departamento de Irrigación del Estado de Jalisco, cuyo objetivo precisamente era fomentar la irrigación en la entidad. ${ }^{5}$

\footnotetext{
${ }^{4}$ Apuntes históricos del estado de Jalisco. 2002. Archivo Histórico de Jalisco (en adelante AHJ), México.

${ }^{5}$ Presidente Cárdenas. Creación del Departamento de Irrigación de Jalisco. 28 de agosto de 1935. Expediente 508/28. Archivo General de la Nación (en adelante AGN), México.
}

\section{()(1) $(9$}


Este departamento tenía como normas básicas invertir el máximo de dinero en trabajo de campo y reducir los gastos de oficina hasta donde fuera posible. En cuanto a las obras de infraestructura, se daría preferencia a las comunidades agrarias y a los pequeños agricultores. De igual forma, se buscaría el abaratamiento de la energía para bombeo y del equipo para la irrigación en general.

En relación con los recursos económicos destinados para la construcción de estas obras, además de los montos aportados por el Estado para la pequeña irrigación, se recibirían otro tipo de subvenciones, como la cooperación de las comunidades agrarias, de los ayuntamientos a través de las juntas municipales y las juntas de obras públicas, las cuales tenían entre sus principales obligaciones hacer posible las obras de pequeña irrigación en el estado de Jalisco.

Esta decisión gubernamental trajo como consecuencia que en los diferentes municipios jaliscienses se diera inicio a una serie de estudios de factibilidad para determinar de qué forma y a partir de qué fuentes se podía utilizar y extraer el agua, considerada, evidentemente, como un recurso estratégico para fomentar el desarrollo agrícola.

En este contexto, en la región de los Altos de Jalisco la mayoría de los municipios, conscientes de lo que este proyecto hidráulico representaba, buscaron sumarse a dicho impulso. Así, el 4 de marzo de 1939 se envió una misiva al presidente Cárdenas desde Teocaltiche, con la petición de que:

Se instale una Escuela Regional Agrícola que prepare a los elementos, a fin de que cuando sean concluidas las obras de irrigación proyectadas haya elementos humanos suficientes para aprovechar la nueva riqueza. Que se funde una Escuela Industrial para aprovechar en la industria la energía eléctrica que producirán las mismas obras de irrigación. Creación de Cooperativas Avícolas y Sericícolas que beneficiarán a los indígenas. Fundación de Escuelas Nocturnas. Que el camino para construcción de la presa a la vía del ferrocarril no sea por Encarnación de Díaz sino por Aguascalientes, debido a que se evita la construcción de numerosos puentes. ${ }^{6}$

Habitantes de otros municipios como Jalostotitlán, San Juan de los Lagos, San Diego de Alejandría, entre otros, hicieron demandas similares.

${ }^{6}$ Presidente Cárdenas. Construcción de escuelas y centros de capacitación. 4 de marzo de 1939. Caja 0591, exp. 508.1/315. AGN, México.

\section{()(1) $(9$}


En respuesta, el presidente solicitó a la Comisión Nacional de Irrigación que se iniciaran estudios de factibilidad en la región. Copia de esta solicitud se envió a cada uno de los presidentes municipales.

Los principales objetivos del proyecto eran los siguientes:

1. La formación en Teocaltiche, Jalisco, de un núcleo que se denominará "El Distrito de Riego de los Altos de Jalisco", integrado por un "Gerente", el cual tendrá bajo sus órdenes a los Ingenieros Delegados que actuarán en cada lugar en que se emprendan estudios u obras. 2. El Gerente se ocupará de la dirección general de las actividades de la Comisión Nacional de Irrigación en el Distrito de Riego, así como en particular de la residencia en Teocaltiche. Los residentes-superintendentes se encargarán de inspeccionar todo el lugar de la región de los Altos en donde existan obras antiguas para el aprovechamiento de aguas. En aquellas obras que no requieran estudios especiales, harán las investigaciones indispensables y se encargarán de dirigir los trabajos de reconstrucción, terminación o mejoramiento que sean necesarios para ponerlos en servicio, de acuerdo con las normas de la Comisión Nacional de Irrigación. Igualmente se dedicarán a estudiar obras nuevas que propongan los habitantes de la región, así como efectuar las exploraciones y estudios iniciales de las obras que juzguen convenientes para el mejor y más rápido desarrollo agrícola de la región de los Altos. ${ }^{7}$

Como se puede apreciar, la primera etapa del proceso de apropiación del agua basado en estudios de factibilidad y planeación de obras de infraestructura tendría como actor principal al Departamento de Irrigación del Estado de Jalisco. Dado que se buscaba aprovechar los cuerpos de agua de la región, se puede comentar que se trataba de un proyecto que implicaba la apropiación del agua para el uso agrícola interno.

El resultado de dicho proyecto fue la construcción del Distrito de Riego de los Altos de Jalisco (013), el cual -junto con el reparto de tierras producto de la reforma agraria- ${ }^{8}$ evidenció que no se incluía de manera equitativa

${ }^{7}$ Presidente Cárdenas. Estudios de factibilidad en la región. 4 de marzo de 1939. Caja 0591, exp. 508.1/315. AGN, México.

${ }^{8}$ La reforma agraria mexicana ha sido un proceso complejo y prolongado. La reforma tuvo su origen en una revolución popular de gran envergadura, y se desarrolló durante una guerra civil. El Plan de Ayala, propuesto por Emiliano Zapata y adoptado en 1911, exigía la devolución a los pueblos de las tierras que habían sido concentradas en las haciendas. En 1912

\section{(1) (1) $(9$}


a todos los municipios de la región. En el mapa 1 se hace patente que en la cobertura no estuvieron comprendidos Cañadas de Obregón, Valle de Guadalupe y Jalostotitlán.

Como se puede ver, el Distrito de Riego suministra agua a la mayor parte de la zona noreste y a algunos otros municipios del estado de Jalisco. En la región norte de los Altos abastece a Teocaltiche y Lagos de Moreno. En la región sur a Yahualica y a San Miguel el Alto.

Como se verá a continuación, la no inclusión de Cañadas de Obregón, Valle de Guadalupe, Jalostotitlán y parcialmente San Miguel el Alto en el Distrito de Riego comenzó a gestarse con el reparto de tierras. Por lo tanto, el papel de apropiadores desempeñado por el Departamento de Irrigación del Estado de Jalisco y la Comisión Agraria Mixta fue fundamental. Asimismo cabe mencionar que entre los usufructuarios más importantes estuvieron la influyente familia González y José María Franco, quienes prácticamente eran dueños de los cuatro municipios.

José Guadalupe González de Anda poseía: "En el municipio de Jalostotitlán: 918-29-50 hs. ${ }^{10}$ en el municipio Valle de Guadalupe 508-02- 05 hs., en el municipio San Miguel el Alto 1613-86-97 hs. Que hacen un total de: 3052-17-52 hs." ${ }^{\prime 11}$

Por su parte, María Trinidad González Tostado acumuló hectáreas sólo en dos municipios, pero abarcaban una extensión importante: "La señorita María Trinidad Tostado adquirió el 18 de abril de 1932, y registró el 31 de mayo del mismo año, diversas compras en los municipios de Jalostotitlán y

algunos jefes militares revolucionarios hicieron los primeros repartos de tierras. En 1915 las tres fuerzas revolucionarias más importantes, el constitucionalismo, el villismo y el zapatismo, promulgaron las leyes agrarias. La atención al pedido generalizado de tierras se convirtió en condición de la pacificación y del restablecimiento de un gobierno nacional hegemónico: la Constitución de 1917 incluyó el reparto de tierras en su artículo 27. Desde entonces, y con sucesivas adecuaciones hasta 1992, el reparto de tierras fue mandato constitucional y política del Estado mexicano (Warman, 2003).

${ }^{9} \mathrm{Al}$ respecto, Chevalier (1999) comenta: "Por este extenso territorio se fueron asentando los colonos españoles que iban llegando a la región. Los primeros de ellos, es decir las familias González, adquirieron por donación real las mejores tierras, fundando con ellas las primeras haciendas que corriendo el tiempo habían de ser las más prósperas” (p. 195).

${ }^{10}$ Se refiere a la cantidad de hectáreas que cada uno de los terratenientes poseía. Debido a que se cita del documento original se respetó la enumeración que los ingenieros de la Comisión Agraria realizaron en aquella época, ellos usaron guiones en lugar de comas para separar números y cantidades.

${ }^{11}$ Jalostotitlán. Dotación de ejidos. 30 de diciembre de 1936. Exp. 1235. AHJ, México.

\section{()ㅜ(1) $(2$}


Mapa 1. Municipios beneficiados por el Distrito de Riego 013
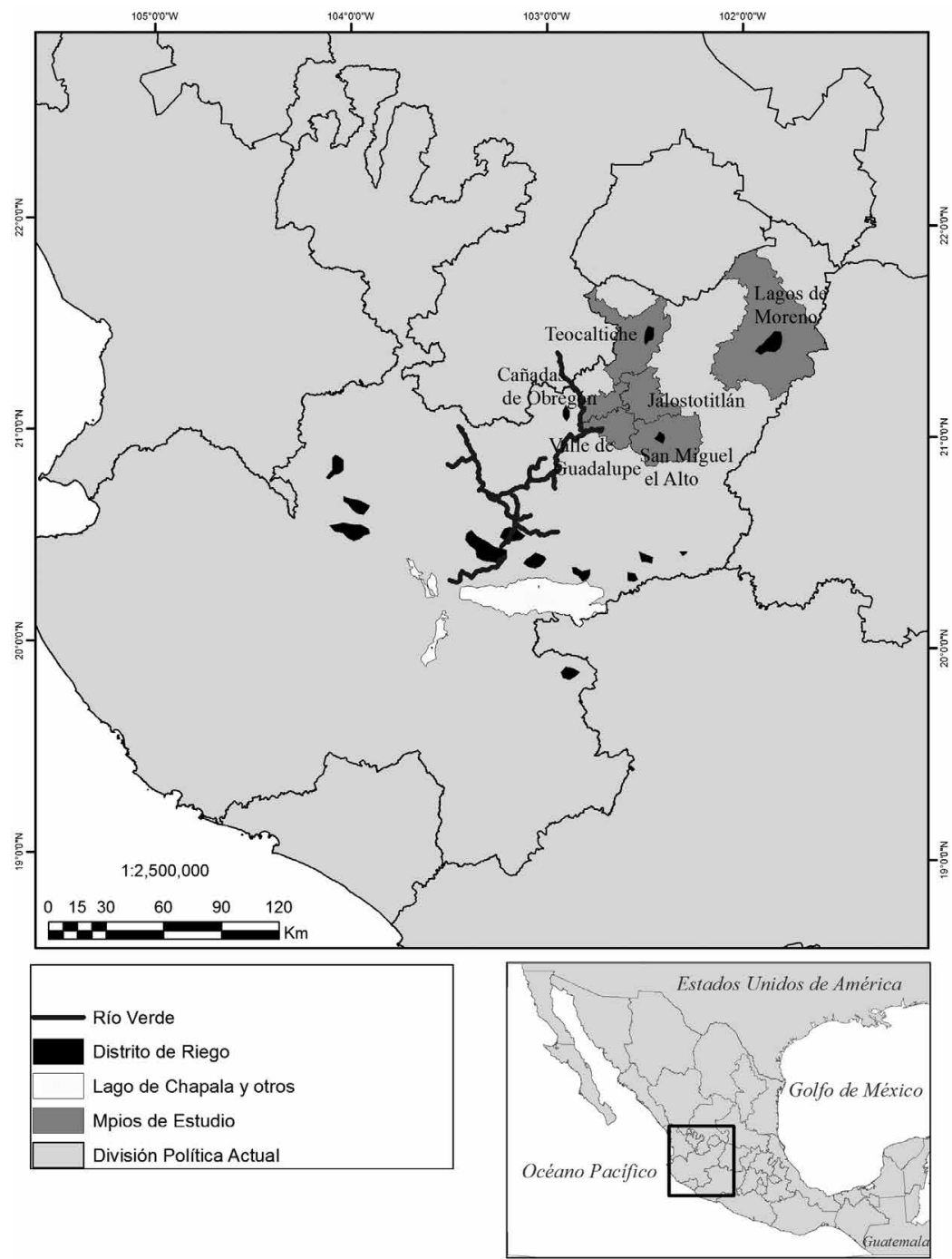

Fuente: elaboración propia con base en ConAGUA, LocRepda.

\section{(ㄷ)(1) $(3$}


San Miguel el Alto, las cuales en su conjunto hacen un total de 2488-18-76 hs. De las cuales 1098-15-55 hs. están ubicadas en el municipio de Jalostotitlán y el resto o sea 1360-03-23 hs. en el de San Miguel el Alto."12

Respecto al municipio Villa de Obregón ${ }^{13}$ (Cañadas de Obregón actualmente), Canuto González contaba con la hacienda El Zapotillo, ubicada al noroeste del municipio -cerca del río Verde-, su superficie era de 938 hectáreas (casi todas de temporal). ${ }^{14}$ Además, poseía terrenos en el municipio colindante de Yahualica. Por su parte, José María Franco era propietario de la hacienda Las Trojes, ubicada en la zona oeste, y cuya extensión superficial era de 782 hectáreas de agostadero (para el pastoreo de ganado). ${ }^{15}$

Por su parte, los desplazados fueron los demandantes de tierra de los cuatro municipios cuyas solicitudes fueron enviadas a la Comisión Agraria Mixta entre 1935 y 1937. Después de realizar estudios técnicos, dicha instancia envió al gobierno del estado de Jalisco las resoluciones y este, a su vez, decidió llevar a cabo, durante diferentes periodos, las dotaciones que se muestran en el cuadro 1.

Como se puede apreciar, los municipios Villa Obregón y Jalostotitlán consiguieron la dotación de tierras en un periodo de tiempo relativamente corto, pero no obtuvieron agua del Distrito de Riego porque a los ejidatarios se les dotó de terrenos de temporal y agostadero, por lo tanto sin acceso al agua. Por su parte, los ejidatarios de Valle de Guadalupe tuvieron acceso a ambos, pero el agua no provenía del Distrito de Riego, sino de las presas Chiquita, Cañada y Grande. ${ }^{16}$ Finalmente, San Miguel el Alto sí formaba parte del Distrito de Riego, pero sus campesinos no fueron dotados de tierra ${ }^{17} y$ agua, esto permite señalar que el beneficio del riego fue para los pequeños propietarios (antes terratenientes). ${ }^{18}$

12 Jalostotitlán. Dotación de ejidos. 30 de diciembre de 1936. Exp. 1235. AHJ, México.

13 El municipio Villa Obregón cambió su nombre a Cañadas de Obregón el año de 1979, como se puede ver en el decreto núm. 10194 del 24 de diciembre de 1979. Por esa razón las fuentes de archivo citadas antes de ese año llevan el nombre de Villa Obregón.

${ }^{14}$ Las tierras de temporal son aquellas que no cuentan con agua de riego, por lo tanto sólo se riegan en época de lluvia.

15 Villa Obregón. Dotación de tierras. 29 de noviembre de 1935. Exp. 973. AHJ, México.

${ }^{16}$ Valle de Guadalupe. Dotación de ejidos. 10 de febrero de 1937. Exp. 100-B. AHJ, México.

17 San Miguel el Alto. Juicio agrario. 9 de julio de 1980. Exp. 1059/93. AHJ, México.

18 San Miguel el Alto. Dotación de aguas. 22 de diciembre de 1992. Exp. 99-B. АнJ, México. 


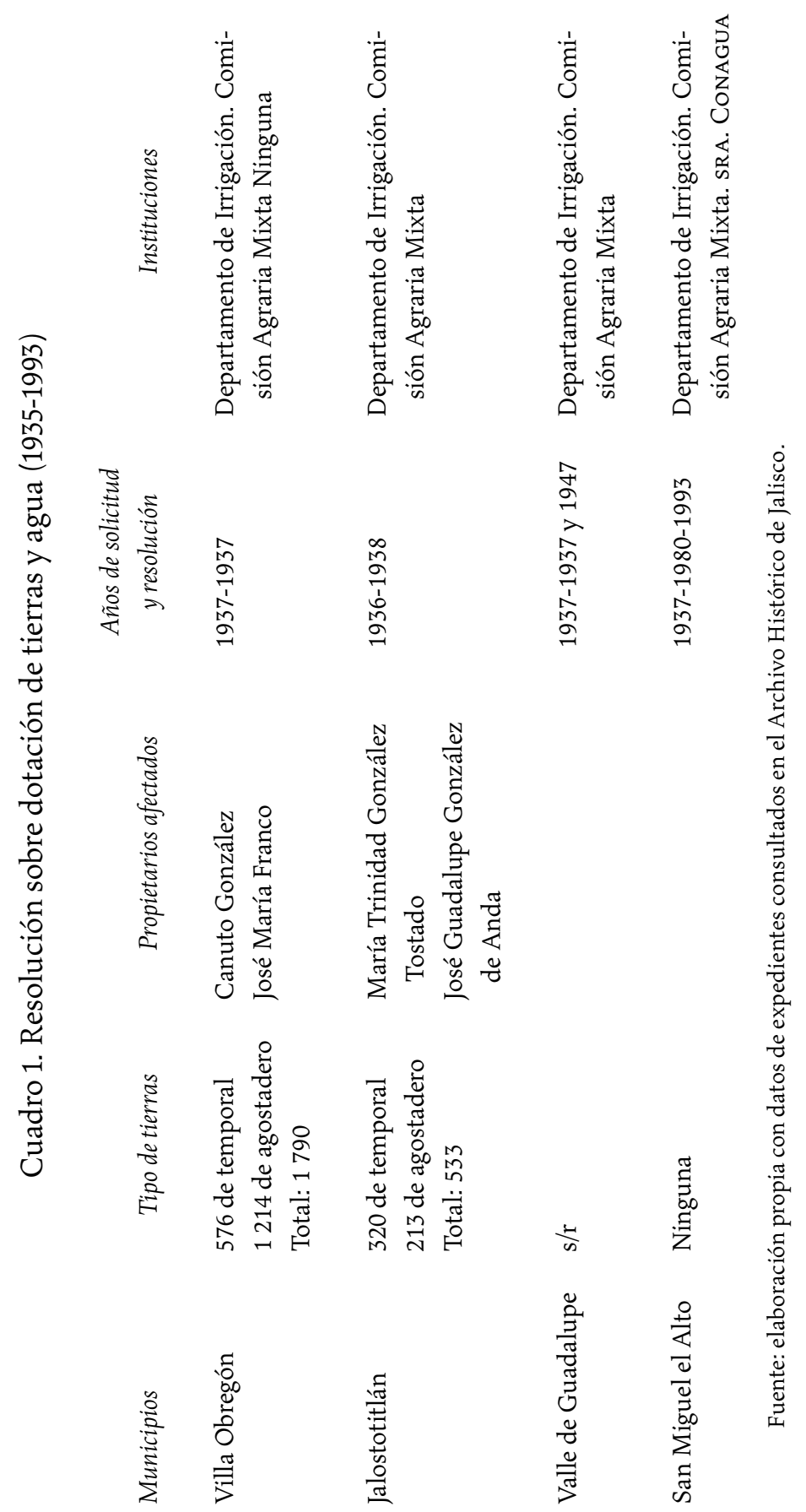

()ㅜ(1) (3) 
Los casos expuestos ponen al descubierto la realidad del reparto de tierras y agua: el agua para riego no siempre benefició a los ejidatarios, a quienes supuestamente se les daba prioridad. Una de las estrategias fue dotar a los campesinos de tierras de temporal, pues al regarse estas tierras con el agua de lluvia, los campesinos no podían reclamar derechos sobre el agua para riego. Otra modalidad consistió en negar las solicitudes y prolongar los juicios agrarios el mayor tiempo posible, para así debilitar o desaparecer a los grupos solicitantes, declarar improcedentes sus solicitudes $y$, por ende, no otorgar las dotaciones. Esto derivó en un paulatino desplazamiento de la producción agrícola de los campesinos, quienes destinaron sus cosechas al autoconsumo, alquilaron su fuerza de trabajo y migraron a otras ciudades del estado o incluso fuera del país.

Respecto a los pequeños propietarios, antes hacendados o terratenientes, ellos trataron de conservar la mayor parte de hectáreas posible, pues les resultaba importante mantener bajo su dominio las tierras de riego y agostadero con buenos pastos para prosperar en la cría de ganado. Por tanto, establecieron relaciones de poder con políticos, familiares y otros propietarios de tierras para conservar las suyas a través de herencias en vida, litigios agrarios, operaciones de compra y venta de terrenos, entre otras argucias. ${ }^{19}$

Las evidencias encontradas permiten deducir que, en la parte que le corresponde a los Altos de Jalisco, en su mayoría el Distrito de Riego fue aprovechado por pequeños propietarios, y que fue la obra hidráulica más significativa en cuanto a la utilización del agua para la agricultura en la región. También se puede señalar que con su construcción se concretó la apropiación del agua en el interior de la región, cuyos beneficios fueron para una minoría de productores agrícolas, es decir, para aquellos cuyo poder económico y relaciones con actores políticos les permitieron ajustarse a las necesidades y obligaciones que el momento económico requirió; por ejemplo, la adaptación de la actividad agrícola de temporal al riego y la combinación de la agricultura y la ganadería, o del rubro agroindustrial, lo que derivó en la modificación de las características del espacio hidrosocial.

${ }^{19}$ Jalostotitlán. Dotación de ejidos. 30 de diciembre de 1936. Exp. 1235. AHJ, México.

\section{(1)(1) $(9$}




\section{TRANSFERENCIA DE AGUA A GUADALAJARA (1940-1980): EL PROYECTO LA ZURDA Y EL INICIO DEL PROCESO DE APROPIACIÓN EXTERNA DEL AGUA}

El inicio de la década de 1940 implicó un nuevo modelo económico para México conocido como sustitución de importaciones, cuyo objetivo era impulsar el desarrollo industrial del país. En un principio (1940-1945) se trató de conseguirlo a partir de las ganancias de la producción agrícola. Este aspecto permite entender el dinamismo del reparto agrario y el apoyo que se otorgó a los nacientes pequeños propietarios con el reparto de tierras y agua, pues se creyó que la mayor parte de ellos contribuiría con una importante producción agrícola y ganadera.

En relación con el manejo y el control del agua, el gobierno mexicano planificó la diversificación de los usos productivos y para este fin implementó otra modalidad de apropiación: el trasvase de agua de una región a otra. Mediante dicha instrumentación se buscaba asegurar la provisión del líquido, pues además de abastecer al sector agrícola, se dotaría de agua a las ciudades, lo que significaba apoyar el crecimiento industrial y, en consecuencia, el urbano. Asimismo, con esta manera de proceder se concretó la separación administrativa del reparto de agua y tierras. Para cumplir con esta tarea, en 1946 se creó la Secretaría de Recursos Hidráulicos (SRH), ${ }^{20}$ la cual sustituyó a la Comisión Nacional de Irrigación.

En los Altos de Jalisco, como ya se vio, las fuentes de agua internas (ríos, lagunas, ojos de agua, entre otras) ya habían sido utilizadas para la

${ }^{20}$ Esta nueva institución se encargaría del almacenamiento y transporte del agua a las crecientes ciudades, cuyo número de habitantes se iba incrementando; otra tarea consistió en satisfacer la demanda de agua de las industrias, las cuales se encontraban en pleno ascenso. La SRH también sustituyó a la Secretaría de Agricultura y Fomento, organismo que hasta entonces era el encargado de regular los aprovechamientos hidráulicos de carácter federal. También -como ya se comentó- se encargaría de las labores que desempeñaba la Comisión Nacional de Irrigación, organismo orientado a construir la infraestructura necesaria para regar tierras de cultivo.

A cargo de la naciente SRH, también quedaba la responsabilidad de potabilizar el agua, actividad que antes correspondía al Departamento de Salubridad, así como el control de inundaciones, antes competencia de la Secretaría de Comunicaciones y Obras Públicas.

Es evidente que la SRH absorbía casi en su totalidad el manejo del agua en el país, con excepción del sector hidroeléctrico, el cual siguió a cargo de la Secretaría de Economía Nacional y de la operación de los distritos de riego, que se le atribuyó a la también naciente SAG (Aboites, 1997, p. 180).

\section{()(1) $(9$}


creación del Distrito de Riego, el cual quedó bajo la administración de otra de las instituciones recién creadas, la Secretaría de Agricultura y Ganadería (SAG). La organización de esta variedad de instituciones derivó en la división de las esferas administrativas del líquido y de la tierra, pues antes de la aparición de la SRH y la SAG, la Comisión Nacional de Irrigación se encargaba de ambas. Por lo tanto, dicha separación implicó la fragmentación del agua y del resto de los elementos de la naturaleza y una interacción diferente entre los actores, ya que los agricultores pasaron a regirse por las normas de la SAG, mientras que los solicitantes de agua tuvieron que remitirse a la SRH, con lo que la relación se hizo más compleja.

De lo anterior se desprende que el agua de los Altos de Jalisco quedó bajo la competencia de dos secretarías, la SAG y la SRH, además de la Comisión Federal de Electricidad (CFE). También debe señalarse que tanto el gobierno federal como el estatal visualizaron al río Verde como una de las opciones para generar energía eléctrica ${ }^{21}$ y de paso abastecer de agua a la ciudad de Guadalajara, fue así que se diseñó en 1944 el Proyecto La Zurda, ${ }^{22}$ el cual permitiría represar las aguas de dicho río.

El inicio del Proyecto La Zurda incluyó al poblado Temacapulín, perteneciente a Villa Obregón, el cual se utilizaría para construir la presa La Zurda, pero al mismo tiempo San Nicolás de los Reyes, poblado de Jalostotitlán, resultaría afectado, ya que con el embalse se inundaría.

Con este proyecto se abrió un escenario en el que se pueden identificar actores como los habitantes de Temacapulín, quienes eran pequeños propietarios que se dedicaban a la agricultura de autoconsumo, la avicultura, la cría de ganado porcino y lechero, así como a otros servicios, por ejemplo, el transporte de pasajeros y la renta de habitaciones a viajeros.

${ }^{21}$ Hernández y Casillas (2008) mencionan: "El proyecto original contemplaba la generación de energía a través de la conducción del agua desde La Zurda hasta la central de Colimilla sobre el Santiago, en cuya ribera se instalaría una planta hidroeléctrica con caída de 350 metros" (pp. 29-30).

${ }^{22}$ El Proyecto La Zurda aprovecharía las aguas de los ríos Valle de Guadalupe, Tepatitlán y Calderón en la enorme vértebra del sistema hidrológico alteño formado en las barrancas del río Verde. Para lograrlo proyectaban la construcción de cuatro presas en distintos sitios cuya capacidad de almacenamiento en las mismísimas tierras áridas, sería de 1155 millones de metros cúbicos de agua. Los estudios para construir sistemas de captación incluían un acueducto hasta Guadalajara, y en el trayecto el agua sería usada para la generación de energía eléctrica que luego serviría en las plantas de bombeo, el manejo de compuertas y los sistemas de seguridad de los diques (Casillas, Hernández y González, 2010, pp. 50-51).

\section{()(1) $(9$}


Algunos de estos pobladores participaron en los trabajos de la construcción de la presa y, de acuerdo con entrevistas realizadas, ellos estaban enterados de que se inundarían San Nicolás de los Reyes y San Gaspar, pero no Temacapulín. "Yo sabía que era de 60 metros. Esa si no supe cuánto iba a inundar, lo que sí es que iba a inundar más o menos, no sé cuántos kilómetros serían, más allá de San Gaspar y San Nicolás, precisamente llegaba hasta San Nicolás." ${ }^{23}$

Otros actores fueron los institucionales, se trató de la CFE, institución que solicitó al ingeniero Elías González Chávez iniciar los trabajos de construcción de la presa La Zurda. Asimismo, la SRH, pues para esta trabajaba González Chávez.

Por su parte, los actores empresariales se hicieron presentes a través de la empresa Ingenieros Civiles Asociados (ICA), la cual fue contratada para ejecutar los trabajos relacionados con la construcción de la presa. Las labores sobre el río Verde se iniciaron en 1956 y se suspendieron en 1959; de acuerdo con el ingeniero José Luis Macías Godínez, ${ }^{24}$ sólo se diseñaron "el túnel de desvío para hacer la toma de la presa, el vertedor y algunos tajos".

De acuerdo con Bogar Armando Escobar Hernández (2012, p. 159), las causas de la suspensión de la primera presa del Proyecto La Zurda fueron de diversa índole: natural, técnica, social y económica. La causa natural se relaciona con el lago de Chapala, ${ }^{25}$ ya que en 1955 experimentó un descenso en su almacenamiento $\left(953.9 \mathrm{~mm}^{3}\right)$, por esa razón se intentó explotar el proyecto de la CFE para trasvasar el agua a Guadalajara. Sin embargo, al final de la década de 1950 el almacenamiento del lago se incrementó $\left(6439.0 \mathrm{~mm}^{3}\right) \mathrm{y}$, en consecuencia, la presa La Zurda se postergó.

La siguiente causa es la técnica. En este sentido, el ingeniero Porfirio Ruvalcaba Barajas señala "el hecho de que el lugar en el que se planteaba construirlo, sobre el río Verde, no era viable geológicamente. Se trataba de terrenos sedimentarios cuyos componentes se encuentran muy separados, lo que pro-

${ }^{23}$ Íñiguez, A. (12 de marzo de 2012). Entrevista al señor Alfonso Íñiguez/Entrevistador: Antonio Rodríguez Sánchez. Temacapulín, Cañadas de Obregón, Jalisco, México.

${ }^{24}$ Macías, J. (15 de mayo de 2006). Entrevista al ingeniero José Luis Macias Godínez/ Entrevistador: Bogar Armando Escobar Hernández, 2012, p. 158.

${ }^{25}$ Durante la década de 1940 y la segunda mitad de la siguiente, la ciudad de Guadalajara fue abastecida con el agua subterránea de Tesistán y posteriormente con la del lago de Chapala (Casillas, Hernández y González, 2010, p. 50).

\section{()(1) $(9$}


voca filtraciones, a diferencia de las rocas ígneas en las que existe un material más compacto y por consiguiente existe menor riesgo de minación." ${ }^{26}$

Además, complementa: "De ahí que el ingeniero Alejandro Villaseñor Martínez, asesor del Consejo de Cámaras Industriales, señalara que en la planeación del proyecto no se tuvieron las bases técnicas para programarlo." ${ }^{27}$

Respecto a la cuestión social, la potencial inundación de los poblados Temacapulín, San Nicolás de los Reyes y San Gaspar fue otro factor para que no se llevara a cabo el Proyecto La Zurda (Escobar, 2012, p. 160). Aunque, como ya se señaló, los habitantes de Temacapulín no estaban enterados de la posibilidad de ser inundados y algunos de ellos trabajaron en la fallida obra. Por lo tanto, en este periodo no hubo movilizaciones de protesta ni resistencia.

en el 56 entró la brecha de la carretera de los Altos, entró una brecha para la construcción de la presa de la Zurda, y ya con la construcción de la presa de la Zurda, mucha gente, pues los que no tenían tierra se dedicaban a trabajar en la presa, de ayudantes del maquinista, otros de veladores, otros encargados de las bombas que estaban sacando el agua, otros de barreteros, porque había barreteros para dinamitar, hubo mucho trabajo, ese trabajo duró del 56 hasta 58 , más o menos. ${ }^{28}$

En cuanto a las cuestiones económicas, las hubo de dos tipos: una institucional y otra empresarial. Respecto a la primera, las versiones de los ingenieros Pedro Vázquez Guerra y Salvador Ochoa Montes permiten identificar que la caída del objetivo principal del Proyecto La Zurda, la generación de energía eléctrica, propició que dejara de ser útil para el gobierno mexicano.

La Zurda la querían para llevar agua a Colimilla, eso quería la CFE, era absurdo porque quería llevar agua a la planta de Colimilla para generar electricidad. Lo que había que hacer era hacer una planta más pequeña porque con el descubrimiento de las aguas del río Grijalva, Chicoasén, Usumacinta y Malpaso, resolvieron el problema del abasto eléctrico a nivel nacional. Por

\footnotetext{
${ }^{26}$ Ruvalcaba, P. (18 de marzo de 2006). Entrevista al ingeniero Porfirio Ruvalcaba Barajas/Entrevistador: Bogar Armando Escobar Hernández, 2012, p. 160.

${ }^{27}$ Ruvalcaba, P. (18 de marzo de 2006). Entrevista al ingeniero Porfirio Ruvalcaba Barajas/Entrevistador: Bogar Armando Escobar Hernández, 2012, p. 160.

${ }_{28}$ Íñiguez, A. (12 de marzo de 2012). Entrevista al señor Alfonso Íñiguez/Entrevistador: Antonio Rodríguez Sánchez, Temacapulín, Cañadas de Obregón, Jalisco, México.
} 
eso dijeron la Zurda es absurda, ya no es conveniente. Con esos ríos se produjo 10 veces más electricidad. ${ }^{29}$

En cuanto a cifras, se "iban a generar $20.5 \mathrm{~m}^{3} / \mathrm{seg}$. siendo que en Chiapas ya se generaba mucho más energía, era una presita muy chiquita que no iba a generar mucha energía y por eso se propuso que el agua se mandara a Guadalajara". ${ }^{30}$ Como se puede notar, dicho argumento revela también por qué el trasvase de agua a Guadalajara fue un objetivo secundario en ese momento.

Finalmente, en el aspecto empresarial hubo un choque de intereses entre los concursantes de la licitación para construir la presa, ya que estaba de por medio la obtención del contrato para tal fin. Por un lado estaba la Cámara Mexicana de la Construcción y, por otro, el Grupo ICA. El contrato fue otorgado a ICA, por lo que desde ese momento la empresa contraria se convirtió en uno de sus principales detractores.

En los trabajos de construcción de la Zurda participó el Grupo de Ingenieros Civiles Asociados, que era muy poderoso, a ellos les dieron la obra y no a la Cámara Mexicana de la Construcción. Esa fue la principal causa de que ya no avanzara bien el proyecto ya que terminó por provocar que se abortara el proyecto porque a los de la cámara no les iba a tocar nada en el reparto del pastel. Por eso decían los empresarios: La Zurda es absurda (Escobar, 2012, p. 160).

En su conjunto, estos factores propiciaron que el Proyecto La Zurda se suspendiera a fines de la década de 1950. No obstante, el río Verde se siguió considerando como fuente de abastecimiento; sobre todo porque: "En 1958 la tasa de crecimiento [de Guadalajara] se disparó y el agua no era ya suficiente para satisfacer la demanda de la población, los servicios, el comercio y la industria." 31

${ }^{29}$ Vázquez, P. (16 de junio del 2006). Entrevista al ingeniero Pedro Vázquez Guerra/ Entrevistador: Bogar Armando Escobar Hernández, 2012, p. 160.

30 Ochoa, S. (21 de marzo de 2006). Entrevista al ingeniero Salvador Ochoa Montes de Oca/Entrevistador: Bogar Armando Escobar Hernández, 2012, p. 160.

${ }^{31}$ Macias, J. (15 de mayo de 2006). Entrevista al ingeniero José Luis Macias Godínez/ Entrevistador: Bogar Armando Escobar Hernández, 2012, p. 158. 
En este sentido se puede señalar que los estudios y proyectos en la región de los Altos de Jalisco han continuado desde la década de $1960^{32}$ y hasta la actualidad. Así, en la década de 1970 surgió el Plan Lerma Asistencia Técnica, ${ }^{33}$ el cual ofrecía abastecer $50 \%$ de la demanda de agua prevista para Guadalajara para el año 2000. Con este proyecto se dejaba de lado la regulación de la corriente del río Verde para la generación de energía eléctrica, pero continuó el propósito de utilizarlo para abastecer de agua al entorno urbano de Guadalajara, acorde con la política de que el abastecimiento de agua ya no privilegiaría a la agricultura como base de la economía mexicana, y que había que reorientarlo hacia el desarrollo industrial y la atención de la creciente población urbana; para ambos rubros se comenzaban a utilizar los recursos presupuestales que la SRH antes destinaba a la irrigación. En este contexto, la presa La Zurda fue considerada el elemento fundamental del proyecto del río Verde, de forzosa presencia en todas las alternativas posibles.

Sin embargo, no se construyeron las obras requeridas debido a que se consideraron lejanas e inviables por su longitud de 100 kilómetros. Al respecto, Sandoval (1980) comenta: "Esto representaba una distancia enorme para la época, máxime si se considera que la conducción era por gravedad y se requerían más de $50 \mathrm{~km}$. de túneles. Por ello hubo oposición por parte del gobierno federal a un proyecto de tal envergadura y 'en provincia”'. (p. 46)

Así pues, el proyecto La Zurda no fue olvidado, por el contrario, se le dio seguimiento y se constituyó en detonador de una serie de proyectos que involucran al río Verde y a otros ríos importantes para la región de los Altos de Jalisco; como se verá más adelante, en la actualidad esto no ha finalizado, sólo que ahora el proyecto tiene el nombre de El Zapotillo.

\section{VIRAJE EN LA POLÍTICA HIDRÁULICA Y PROYECTOS EN LOS ALTOS DE JALISCO (1989-2017)}

Durante la década de 1980 se experimentaron transformaciones en diversos ámbitos a escala mundial; algunas de ellas implicaron el fin del papel de los

\footnotetext{
32 Respecto a este tema, entre otros autores, véanse Casillas (2002); Durán y Torres (2006); Escobar (2012); Sandoval (1980).

${ }_{33}$ Esto como "resultado de las negociaciones del gobierno ante el BID, para buscar el mejoramiento integral de las gentes que vivían dentro de la cuenca Lerma-Santiago y las regiones adyacentes" (Rangel, 2005, p. 344. Citado en Durán y Torres, 2006, p. 357).
}

\section{()(1) $(9$}


Estados como encargados de que la sociedad accediera a bienes y servicios básicos para la vida. El manejo del agua no fue ajeno a esta serie de cambios político-administrativos.

Así comenzó un proceso de reestructura de las instituciones encargadas del manejo del agua y de la política hidráulica nacional. En ese contexto, en 1989 se creó la Comisión Nacional del Agua (CNA) a fin de contar con una autoridad federal única en el ramo, pero con un enfoque distinto al de sus antecesoras la SRH, 1946-1976, y al de la Secretaría de Agricultura y Recursos Hidráulicos (SARH), 1976-1989. La CNA tenía la misión de planificar políticas públicas "acordes" a los requerimientos de la sociedad mexicana.

En 1992 la CNA cambió su nombre por el de Comisión Nacional del Agua (ConAgua), ${ }^{34}$ además se introdujo la nueva Ley de Aguas Nacionales (LAN), que entre sus principales postulados tenía garantizar el encuadre jurídico de la propiedad privada del agua a través del involucramiento del sector privado en su abastecimiento; al mismo tiempo la introduciría en los mecanismos de mercado, es decir, la privatización y la comercialización primarían en el manejo del líquido.

Estos cambios en la política hidráulica nacional representaron un punto de quiebre para los Altos de Jalisco. El objetivo siguió siendo la exportación del agua del río Verde a la ciudad de Guadalajara, pero el entramado social y las relaciones de poder establecidas a lo largo del tiempo sí se modificaron y con ello los papeles desempeñados por los actores involucrados, al igual que las formas de apropiación del líquido, tal y como lo demuestran cinco proyectos de trasvase de agua que se llevaron a cabo en la región entre 1989 y 2017. Cabe mencionar que si bien hubo otros, aquí sólo se hace referencia a los que han constituido el eje central del proyecto regional y que se han planeado en detrimento de los municipios que se vienen analizando: Valle de Guadalupe, Jalostotitlán y Cañadas de Obregón (para este contexto ya no se llamaba Villa Obregón). Los proyectos identificados en ese sentido se muestran en el cuadro 2.

${ }^{34}$ Las principales funciones de esta institución son: 1) la descentralización de la administración, 2) fomentar una mayor confianza en la valoración y por lo tanto una recuperación del costo total, 3) más participación por parte de los usuarios y 4) tratar el agua como un bien económico. Este marco parte principalmente de una práctica bien establecida de préstamos para soluciones tecnocráticas y control de las agencias públicas, significando un cambio legislativo que lleva a la administración del agua del sector público al sector privado y la redefine pasando de ser un bien público a ser una mercancía.

\section{()(1) $(3$}




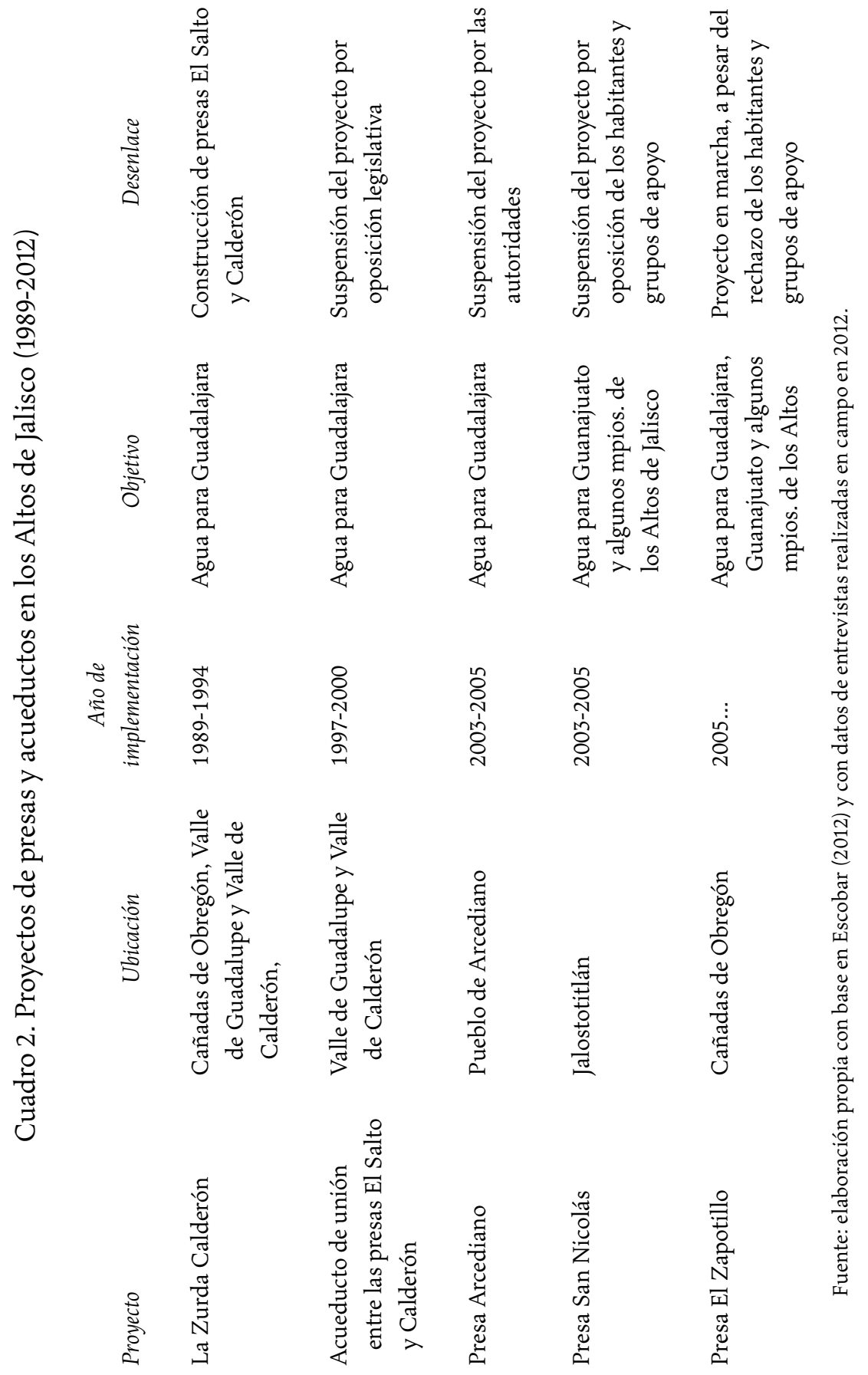

(c) (1) 
Como se puede observar, cada uno de estos proyectos se realizó en diferentes etapas y se planificaron diferentes obras de infraestructura, como presas y acueductos. Además, los objetivos de abastecimiento fueron cambiando con el paso del tiempo, por ejemplo del trasvase a Guadalajara se pasó a incluir en el abastecimiento a municipios industrializados y con potencial agrícola de los Altos de Jalisco, como San Juan de Los Lagos, Lagos de Moreno y Teocaltiche, e incluso a la ciudad de León, Guanajuato. Así pues, se puede decir que el grupo de los usufructuarios se incrementó y diversificó.

Asimismo, según el objetivo de cada proyecto, se hicieron modificaciones en cuanto a los municipios que resultarían afectados; otros elementos han permanecido constantes. En este sentido se puede mencionar el objetivo de trasladar el agua a Guadalajara y que Cañadas de Obregón está presente en tres de los proyectos, entre ellos el que está en marcha, es decir, El Zapotillo. Por lo tanto, es el lugar donde históricamente se ha planificado construir una presa y donde se encuentran los potenciales habitantes desplazados.

En relación con los municipios que aquí se estudian, Valle de Guadalupe ya fue impactado con la construcción de la presa El Salto (1993); en el caso de Jalostotitlán, esto se evitó con la suspensión de la construcción de la presa San Nicolás en 2005. En Cañadas de Obregón, hasta este año (2017) se continúa construyendo la cortina de la presa El Zapotillo, y está pendiente el acueducto que llevará el agua a los municipios pertenecientes a los Altos de Jalisco, Guadalajara y León (Guanajuato).

\section{EL ZAPOTILLO: EL REGRESO DEL PROYECTO DE TRANSFERENCIA DEL AGUA DEL RÍO VERDE}

Después de que en 2005 el gobernador del estado de Jalisco, Francisco Ramírez Acuña, suspendió la construcción de la presa San Nicolás en Jalostotitlán, dicho proyecto fue transferido al municipio Cañadas de Obregón con el nombre de El Zapotillo. Esto significó su regreso a la entidad en que había nacido en 1956, cuando se le denominó La Zurda. El sitio elegido para el embalse fue justamente el predio ejidal El Zapotillo.

\section{()(1) $(9$}


Las características ${ }^{35}$ y funciones de la obra serían prácticamente las mismas que las de San Nicolás, es decir, trasladar el agua almacenada a León a través de un acueducto que atravesaría los Altos de Jalisco. Asimismo, se buscaría suministrar agua a algunos municipios de los Altos, como San Juan de Los Lagos, Lagos de Moreno y Encarnación de Díaz, por mencionar algunos (véase mapa 2).

Cuando se dio a conocer el Proyecto El Zapotillo, se mencionó que la cortina de la presa tendría una altura de 80 metros, de esta forma inundaría únicamente al rancho Palmarejo -ubicado en Cañadas de Obregón-y al pequeño pueblo de Acasico - asentado en Mexticacán- con los cuales supuestamente se podría negociar. Además, se decidió que el pueblo de Temacapulín, enclavado en Cañadas de Obregón y colindante con el sitio donde se construye la presa, sería protegido por diques de concreto, es decir, no resultaría perjudicado por el embalse. ${ }^{36}$

Sin embargo, en 2007, Emilio González Márquez -de filiación panista y entonces gobernador del estado de Jalisco- declaró que el tamaño de la cortina aumentaría y pasaría de 80 a 105 metros; en consecuencia el embalse de la presa sería de mayor extensión y Temacapulín sería inundado. ${ }^{37}$ Así se inician los momentos de tensión.

En el cuadro 3 se puede apreciar quiénes son los actores involucrados en el Proyecto El Zapotillo.

Así, aparecen actores políticos como Felipe Calderón Hinojosa, José Luis Luege Tamargo, Emilio González Márquez y César Coll Carabias, cuya función es la de apropiadores del agua. El mismo papel lo desempeña Raúl Antonio Iglesias Benítez, de quien se desconoce si tiene vínculos partidistas, pero según el tiempo que duró en sus funciones (diez años), se puede ver que ejerció un gran poder en la región respecto al manejo y control del agua.

En cuanto a los empresarios, Grupo ICA participó en el concurso de licitación, pero este fue ganado por Jorge Hank Rhon. Las otras empresas son transnacionales de capital español conocidas por los trabajos relacionados con la gestión del agua (entre otros servicios de corte ambiental) en América Latina. Dichas empresas tienen una doble función: la de apropiadores y la

${ }^{35}$ La descripción oficial del proyecto se puede consultar en http://agua.guanajuato.gob.mx/

${ }^{36} \mathrm{http} / / /$ noalapresaelzapotillo.wordpress.com/cronologia/

37 Íñiguez, A. (12 de marzo de 2012). Entrevista al señor Alfonso Íñiguez/Entrevistador: Antonio Rodríguez Sánchez. Temacapulín, Cañadas de Obregón, Jalisco, México.

\section{()(1) $(9$}




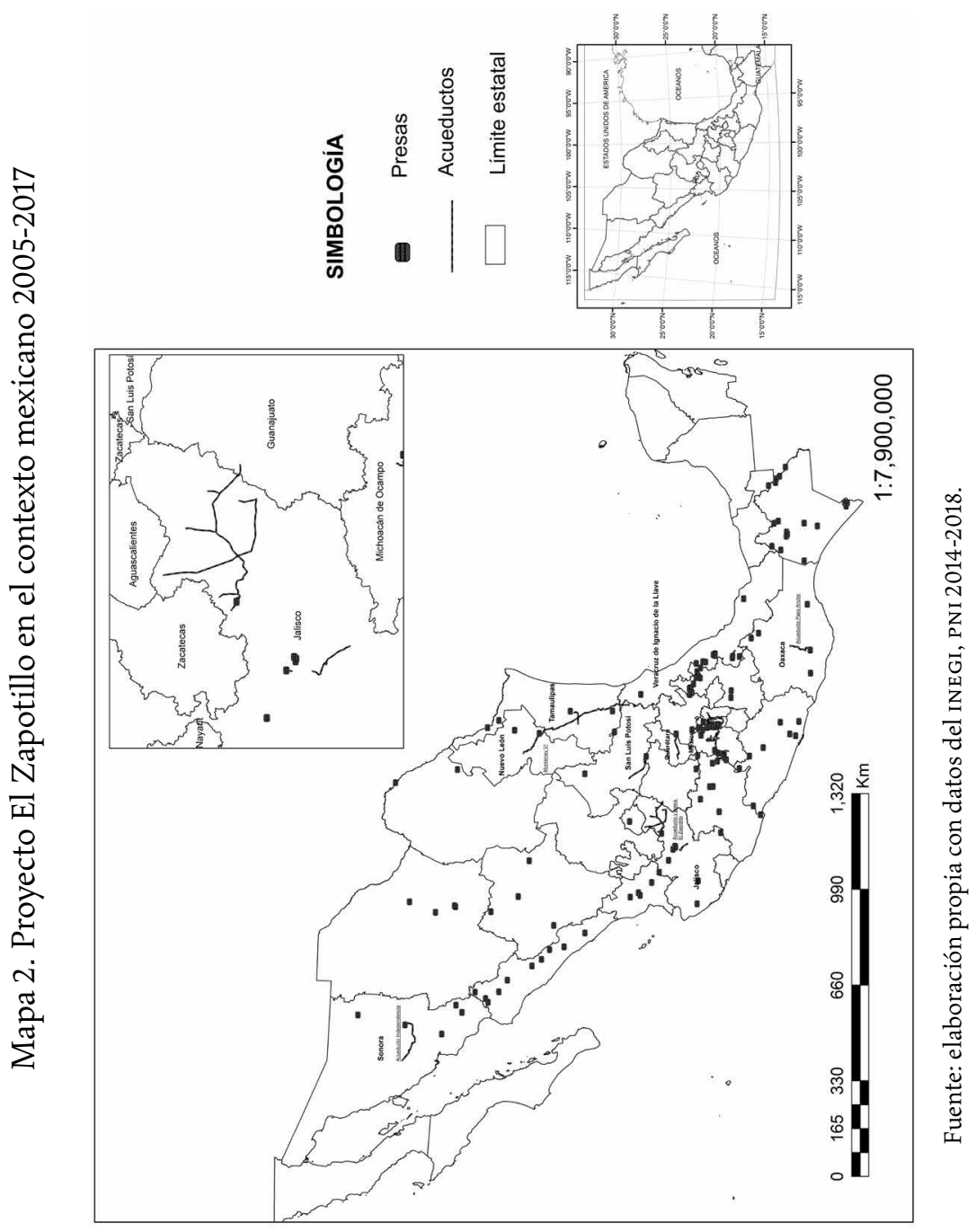

\section{(c) (1) $\$$}




\section{Cuadro 3. Actores involucrados en el Proyecto El Zapotillo (2005-2012)}

El Zapotillo

Actores

Felipe Calderón Hinojosa

José Luis Luege Tamargo

Emilio González Márquez

César Coll Carabias

Raúl Antonio Iglesias Benítez

Sociedad civil, académicos y funcionarios expertos en temas hidráulicos que advierten la inviabilidad del proyecto Obras construidas

Jorge Hank Rohn y socios españoles

\section{Cargo}

Presidente de México 2006- 2012 (PAN)

Director de la ConAgua (2006-2012)

Gobernador del Estado de Jalisco 2007-2013 (PAN)

Comisión Estatal del Agua de Jalisco 2007-2013 (CEAs)

Gerencia regional de la Comisión Nacional del Agua (2002-2012). Convertida en 2007 en el Organismo de Cuenca Lerma Santiago Pacífico.

Conservar sus tierras para sus actividades económicas y no ser desplazados

Construcciones parciales de la cortina de la presa y el centro de reubicación

Empresas: Peninsular, Grupo Hermes, FCC y Abengoa-Construcción de la presa, acueducto y licitación para gestionar el agua

Fuente: elaboración propia con datos de entrevistas realizadas en campo en 2012. 
de usufructuarios; pues aparte de construir las obras de infraestructura se encargarán de la gestión del agua -los detalles se verán más adelante.

Por último, en el papel de los afectados se encuentran los habitantes de Temacapulín, quienes en la actualidad se mantienen en resistencia. Para ello han contado con el apoyo de organizaciones como el Comité de Hijos Ausentes de Temacapulín, ${ }^{38}$ el Colectivo de Organizaciones Ciudadanas por el Agua (Coloca) ${ }^{39}$ y Colectivo COA, ${ }^{40}$ por mencionar algunas. Los pobladores de Palmarejo (rancho abandonado) y Acasico negociaron sus tierras y abandonaron el movimiento. ${ }^{41}$

Respecto a las obras, en el cuadro se puede apreciar que se está trabajando en la construcción de la cortina de la presa y en el centro de reubicación para los desplazados; por lo tanto, en comparación con los proyectos de Arcediano y San Nicolás, ${ }^{42}$ El Zapotillo tiene más avances.

A lo largo de estos diez años (2007-2017) los actores señalados han variado y otros se han mantenido, de modo que los trabajos, las negociaciones y las relaciones de poder en torno al Proyecto El Zapotillo han pasado por diferentes arenas de disputa.

Entre ellas, la formación del Comité Salvemos Temacapulín sirvió a los habitantes para articularse con otras organizaciones con problemas similares, difundir su problemática dentro y fuera del país, establecer diálogos con las diferentes instancias gubernamentales, así como la defensa jurídica y política de los derechos colectivos en contra de la construcción de la presa.

Por su parte, las instituciones gubernamentales encargadas del proyecto han respondido con hostigamiento, amenazas, negociaciones clandestinas con algunos de los habitantes de Temacapulín para incitarlos a que vendan sus terrenos, violación de medidas cautelares emitidas por la Comisión

${ }^{38}$ I. de Loza, "Lucha contra El Zapotillo recibe ayuda internacional", El Informador, 6 de junio de 2011. Recuperado de http://www.informador.com.mx/jalisco/2011/297900/1/ lucha-contra-el-zapotillo-recibe-apoyo-internacional.htm

${ }^{39}$ E. Águila, "Rechazan organizaciones presas de Arcediano y El Zapotillo", El Informador, 11 de septiembre de 2008. Recuperado de http://www.informador.com.mx/jalisco/2008/37707/1/rechazan-organizaciones-presas-de-arcediano-y-el-zapotillo.htm

${ }^{40}$ Redacción, "Afectados por presa El Zapotillo pretenden defensa internacional", El Informador, 30 de enero de 2009. Recuperado de http://www.informador.com.mx/jalisco/2009/74414/1/afectados-por-presa-el-zapotillo-pretenden-defensa-internacional.htm

${ }^{41}$ A partir de este momento, el comité de defensa pasó a llamarse "Salvemos Temacapulín" en vez de "Salvemos Temacapulín, Palmarejo y Acasico".

${ }^{42}$ Véase cuadro 2. Estos proyectos son parte de los cinco que se realizaron entre $1989 \mathrm{y}$ 2017. 
Estatal de Derechos Humanos del estado de Jalisco, entre las cuales se menciona que detengan los trabajos de la obra hasta consultar a los habitantes de las comunidades afectadas. Asimismo, en el año 2009 se abrió el concurso de licitación, así aparecen en escena las empresas Peninsular y Grupo Hermes y la española Fomento de Construcciones y Contratos S. A. (FCC). ${ }^{43}$ Por su parte, Abengoa será la encargada de construir el acueducto que lleve el agua a la ciudad de León, Guanajuato, y municipios de los Altos.

Estas arenas de disputa no han impedido que la construcción de la cortina de la presa se detenga; para el 20 de enero de $2013^{44}$ registraba un avance de 54.6 por ciento.

En ese mismo año se dio el regreso del PRI al poder en Jalisco con Aristóteles Sandoval (2013-2018), lo que abrió un nuevo camino en las negociaciones. Así, el actual gobernador de Jalisco propuso reducir la cortina de 105 a 80 metros, tal y como se había planteado en el proyecto original. Aunque posteriormente señaló que la decisión final dependería de la ConAguA. ${ }^{45}$

Además, el gobierno de Jalisco ofreció a la ConAgua la alternativa de construir tres presas más, las cuales serían intermedias a la presa El Purgatorio, a cambio de reducir la cortina de El Zapotillo. ${ }^{46}$ Con ello se evitaría la inundación de Temacapulín. Dichas negociaciones están por definirse y tal vez pronto se tenga una resolución.

A pesar del resguardo de Temacapulín y de esta nueva etapa de negociaciones, parece que la historia se repite, pues con la reducción de la cortina de El Zapotillo se tendrán que construir tres presas más, aparte de El Purgatorio, lo que implicaría que otras poblaciones estarían en peligro de ser desplazadas. Así pues, el proceso de apropiación del agua basado en el diseño de proyectos hidráulicos en los Altos de Jalisco no se ha detenido.

${ }^{43}$ Redacción, "Ya hay constructor para El Zapotillo", El Informador, 15 de septiembre de 2009. Recuperado de www.informador.com.mx/jalisco/2009/137657/1/ya-hay-constructor-para-el-zapotillo.htm

${ }^{44}$ I. de Loza, "Temacapulín no se inunda: Aristóteles", El Informador, 29 de enero de 2013. Recuperado de http://www.informador.com.mx/jalisco/2013/433573/6/temacapulinno-se-inunda-aristoteles.htm

${ }^{45}$ Redacción, "El Zapotillo, en manos de Conagua", El Informador, 8 de febrero de 2013. Recuperado de http://www.informador.com.mx/jalisco/2013/435776/6/el-zapotillo-en-manos-de-conagua.htm

${ }^{46}$ Redacción, "El Purgatorio puede dar entre dos y tres mil litros de agua a la ciudad", El Informador, 26 de marzo de 2013. Recuperado de www.informador.com.mx/jalisco/2013/446941/1/ el-purgatorio-puede-dar-entre-dos-y-tres-mil-litros-de-agua-a-la-ciudad.htm

\section{()(1) $(9$}


Otro factor a considerar es que el gobierno federal está preparando las condiciones jurídicas para que la protesta social ya no sea un elemento que interrumpa el proceso de apropiación del agua a través de los trasvases u otros medios encabezados por las instituciones que lo representan y empresas privadas. De este hecho queda constancia con las reformas propuestas a la Ley General de Aguas, ${ }^{47}$ las cuales se dieron a conocer en abril de 2015 y que hasta lo que va del 2017 no han sido aceptadas. En relación con las protestas sociales, en las reformas a la citada ley se propone que: "Para hacer cumplir sus determinaciones, las autoridades federales, estatales, del Distrito Federal o municipales, podrán solicitar el auxilio de la fuerza pública." ${ }^{48}$

Como se puede ver, en la nueva reglamentación se criminaliza la protesta social, por lo tanto, acciones como las de los actores opositores referidos en este trabajo no serán permitidas. En el mismo sentido, entre sus puntos referentes al tema de trasvases, la citada ley tiene la facultad de convertir en concesionaria a la empresa encargada de construir una obra hidráulica cuya finalidad sea el trasvase de agua. Así, en su texto se asienta que: "Los trasvases son considerados de utilidad pública, los trasvases 'directos' serán concesionados a privados; los trasvases 'indirectos' serán manejados por la Federación con inversión pública o privada en beneficio de los 'concesionarios". ${ }^{49} \mathrm{Y}$ en otra parte se especifica que: "La compra-venta de concesiones de trasvase sólo requiere notificar a la CONAGUA. ${ }^{50}$

Como se puede apreciar, los artículos 80 y 98 de la propuesta de la Ley General de Aguas no hacen más que legalizar los mecanismos utilizados por las instituciones federales y estatales encargadas del manejo del agua y las empresas concesionarias durante el proceso de apropiación del líquido; es decir, la nueva ley protege el intercambio de funciones entre apropiadores y

${ }^{47}$ El contenido de los artículos que se mencionaron se puede ver en E. Burns (15 de abril de 2015). Análisis de la iniciativa Conagua de la Ley General de Aguas. Agua para todos, Agua para la vida. Recuperado de http://aguaparatodos.org.mx/la-iniciativa-ciudadana-de-ley-general-de-aguas/

${ }_{48}$ Artículo 24. Citado en E. Burns (15 de abril de 2015). Análisis de la iniciativa ConAGUA de la Ley General de Aguas. Agua para todos, Agua para la vida. Recuperado de http://aguaparatodos.org.mx/la-iniciativa-ciudadana-de-ley-general-de-aguas/

49 Artículo 98. Citado en E. Burns (15 de abril de 2015). Análisis de la iniciativa ConAgUA de la Ley General de Aguas. Agua para todos, Agua para la vida. Recuperado de http://aguaparatodos.org.mx/la-iniciativa-ciudadana-de-ley-general-de-aguas/

${ }^{50}$ Artículo 80. Citado en E. Burns (15 de abril de 2015). Análisis de la iniciativa ConAGUA de la Ley General de Aguas. Agua para todos, Agua para la vida. Recuperado de http://aguaparatodos.org.mx/la-iniciativa-ciudadana-de-ley-general-de-aguas/

\section{()(1) $(9$}


usufructuarios, relación de la que se benefician las empresas ya que se pueden apropiar el agua y, al mismo tiempo, usufructuarla a través de la figura de "concesionarios".

Asimismo, estos artículos permiten identificar las ventajas de que gozarán La Peninsular y Grupo Hermes -ambas propiedades de Jorge Hank Rhon-, así como las empresas españolas FCc y Abengoa, todas ellas encargadas del Proyecto El Zapotillo. De hecho, la nueva ley protege las inversiones realizadas por las empresas usufructuarias o "concesionarias"; esto se puede ver en artículos como el 34, el cual hace alusión al fortalecimiento de los prestadores del servicio, es decir, a brindar garantías para sus ganancias.

Sobre el mismo tema cabe mencionar el artículo 110, el cual ofrece contratos de inversión recuperable y contratos para ampliar la prestación de servicios. Igualmente, el 229, que otorga fondos para riesgos y la garantía de que si se suspende algún contrato, la empresa internacional podrá demandar al gobierno mexicano ante los tribunales internacionales alegando su derecho a las "utilidades esperadas"; de ahí la importancia de los socios españoles de Jorge Hank Rhon, pues por su carácter de empresario mexicano él no podría demandar.

Así pues, los argumentos anteriores permiten sugerir que las reformas propuestas a la todavía no aceptada Ley General de Aguas constituyen una amenaza para las actuales negociaciones entre los habitantes de Temacapulín, el gobierno del estado de Jalisco y la ConAGUA. Aunque también liberan el camino al proceso de apropiación del agua que se ha venido gestando en los Altos de Jalisco, ya que como se pudo ver los artículos están diseñados para terminar con todo tipo de oposición social, negociaciones y cabildeos.

Finalmente, en su conjunto, lo expuesto representa un desafío actual y futuro para los habitantes de Temacapulín, de la región de los Altos de Jalisco y aun de todos los mexicanos, pues la apropiación del agua por parte de unos cuantos en detrimento de la mayoría constituye un riesgo para la vida misma.

\section{REFLEXIONES FINALES}

La configuración hidrosocial del espacio resulta del proceso de apropiación del agua que realiza un sector de la sociedad en detrimento de otro. Dicho proceso se inicia con la administración independiente del agua a través de la

\section{()(1) $(3$}


cual se separa de la naturaleza; posteriormente, se expande mediante transferencias y se intensifica con la construcción de infraestructura.

Durante este proceso, el agua es incorporada socialmente por medio de relaciones tales como las de trabajo, de poder, productivas o culturales, por citar algunas. Estas proporcionan variables de análisis cuya complejidad se entiende mejor al explorar sus transformaciones históricas. Tal como se ha mostrado en este trabajo, entre 1935 y 2017 se ha vivido un largo proceso de apropiación del agua en los Altos de Jalisco, el cual es motivado por diferentes objetivos políticos y económicos.

Durante estos 82 años, los actores participantes han construido diferentes escenarios de disputa. En 1935 la implementación de la reforma agraria y la política de irrigación favorecieron la apropiación de las fuentes de agua de los Altos de Jalisco a través de la construcción del Distrito de Riego 013. Con ello se evidenció que la política de irrigación se dirigía sólo a un sector de agricultores cuya solvencia les permitía adaptarse a las necesidades económicas del momento, mientras que a los campesinos carentes de tierra se les dieron terrenos de temporal, sin derecho a agua de riego, lo que gradualmente los obligó a practicar la agricultura de subsistencia y a emigrar a otras ciudades dentro y fuera del país.

La mayor parte de estos campesinos fueron habitantes de los municipios Cañadas de Obregón, Jalostotitlán, Valle de Guadalupe y San Miguel el Alto, es decir, el área central de los Altos de Jalisco, cerca del río Verde. La ubicación de estos municipios ha hecho que históricamente sus territorios sean considerados sitios estratégicos para la construcción de infraestructura hidráulica, como presas y acueductos. Por lo tanto, sus pobladores sin recursos económicos han visto cómo las desigualdades se han ido incrementando; primero, las desavenencias se hicieron patentes con el reparto de tierras y el acceso al agua de riego y, posteriormente, durante diferentes etapas, sus territorios han sido codiciados para construir infraestructura hidráulica, lo que los ha convertido en potenciales desplazados de sus lugares de origen.

Aquí se han expuesto algunos aspectos del análisis de la configuración hidrosocial del espacio, mismos que permiten discernir que el proceso de apropiación del agua llevado a cabo por instituciones gubernamentales y actores económicos se basa en estrategias antidemocráticas, en tanto que excluye a la mayoría de los ciudadanos al considerar la exploración, explotación y usufructo del agua exclusivos de la burocracia hídrica y de los empresarios; pese a ser los posibles agraviados, quienes constituyen la mayoría no

\section{()(1) $(9$}


son involucrados en la toma de decisiones, y sus conocimientos locales sobre el manejo y dinámica de las fuentes de agua son soslayados.

Asimismo, se muestra la forma en que la dinámica capitalista actualmente agiliza y expande el proceso de apropiación mediante el otorgamiento de derechos de propiedad del agua; esto trae como consecuencia la paulatina eliminación del derecho social al agua pues esta se convierte en un bien privado. Por ejemplo, la incursión de empresas españolas en el actual Proyecto El Zapotillo demuestra la expansión de la apropiación del agua, es decir, que se trata de un proceso a escala planetaria. En este sentido, el análisis de la configuración hidrosocial del espacio cobra relevancia al tratarse de un concepto global que va más allá del territorio, paisaje o cuenca.

De este modo, la suspensión y el retraso en la ejecución de algunos proyectos en la región de los Altos de Jalisco - por ejemplo, la suspensión de la construcción de las presas San Nicolás en Jalostotitlán y el retraso de El Zapotillo en Cañadas de Obregón- abre un panorama optimista. Esto sobre todo en el caso de El Zapotillo, el cual se ha vinculado con luchas internacionales, lo que permite argumentar que la vinculación entre movimientos de resistencia globales con problemas comunes es una magnífica opción para enfrentar y revertir el proceso de apropiación del agua.

\section{LISTA DE REFERENCIAS}

Aboites, L. (1997). El agua de la nación. Una historia política de México (1888-1946). México: CIESAS.

Casillas Báez, M. A. (2002). La tercera revolución del agua. Sociedad y medioambiente en los Altos de Jalisco. Zapopan: El Colegio de Jalisco/Comisión Estatal de Agua y Saneamiento.

Casillas, M. A. y González C. (2009). Del campo a la ciudad. Reflexiones en torno a la gestión del agua en los Altos de Jalisco. Ponencia presentada en el 53 Congreso Internacional de Americanistas, Ciudad de México, México.

Casillas, M. A., Hernández, J. J. y González, C. (2010). El manejo del agua en Jalisco: un asunto de poder. En M. A. Casillas y G. Espinoza (coords.), Los ojos del mundo están puestos en Temaca. La resistencia en los Altos de Jalisco en contra de la presa El Zapotillo (pp. 10-52). León: Imprenta Azteca.

Chevalier, F. (1999). La formación de los latifundios en México. Haciendas y sociedad en los siglos XVI, XVII y XVIII. México: FCE.

\section{(1)(1) $(9$}


Durán, J. M. y Torres, A. (2006). ¿Agua para Guadalajara? En D. Barkin (coord.), La gestión del agua urbana en México. Retos, debates y bienestar. Guadalajara: Udeg.

Escobar Hernández, B. A. (2012). Los señores del agua. Relaciones de poder en el abasto hídrico de la zona metropolitana de Guadalajara. Guadalajara: Centro Universitario de Ciencias Sociales y Humanidades-Coordinación Editorial-udeg.

Harvey, D. (2001). La geografía de la acumulación capitalista: reconstrucción de la teoría marxiana. En D. Harvey, Espacios del capital (pp. 255-284). Madrid: Akal.

Hernández, J. J. y Casillas, M. (2008). La presa que se llenó de engaños: el caso de San Nicolás, Jalisco. Respuesta regional a los proyectos estatales de trasvases. Relaciones. El Colegio de Michoacán, XxIx(116), 23-62.

Lefebvre, H. (1971). De lo rural a lo urbano. Barcelona: Ediciones Península.

Lefebvre, H. (1993). The production of space. Oxford: Basil Blackwell.

Ramírez, G. (16 de febrero de 2013). Gobierno del Estado de Jalisco. Regiones de Jalisco. Recuperado de http://www.jalisco.gob.mx/es/jalisco/regiones

Sandoval, F. (1980). El proyecto La Zurda. Guadalajara: Gobierno de Jalisco/Textos de Jalisco.

Santos, M. (1986). Espacio y método. GEO-Crítica, 65, 5-53. Recuperado de http:// www.ub.edu/geocrit/geo65.htm

Smith, N. (2006). La producción de la naturaleza, la producción del espacio. México: Facultad de Filosofía y Letras-UNAM.

Toledo, V. (2002). La modernización rural de México: un análisis socioecológico. México: SEMARnat.

Swyngedouw, E. (2009). The political economy and political ecology of the hydro-social cycle. Journal of Contemporary Water Research \& Education, 142, 56-60. DOI: http://doi.org/10.1111/j.1936-704X.2009.00054.x

Warman, A. (2003). La reforma agraria mexicana: una visión de largo plazo. Recuperado de http://www.fao.org/docrep/006/j0415t/j0415t09.htm

\section{OTRAS FUENTES}

Archivos

AGN Archivo General de la Nación, México.

AHJ Archivo Histórico de Jalisco, Guadalajara, México.

\section{()(1) $(3$}




\section{Entrevistas}

Íñiguez, A. (12 de marzo de 2012). Entrevista al señor Alfonso Íñiguez/ Entrevistador: Antonio Rodríguez Sánchez, Temacapulín, Cañadas de Obregón, Jalisco, México.

\section{Páginas Web}

http://ceas.jalisco.gob.mx/reg12.html [Consulta: 23 de septiembre de 2011.]

http://noalapresaelzapotillo.wordpress.com/cronologia [Consulta: 18 de octubre de 2011.]

http://agua.guanajuato.gob.mx/ [Consulta: 14 de mayo de 2015.] 